\title{
Ácidos graxos e colesterol da carne de cordeiros confinados recebendo dietas contendo fontes lipídicas e submetidos à restrição e realimentação
}

\author{
Fatty acids and cholesterol of meat from lambs fed diets containing lipid \\ sources and subjected to restriction and refeeding
}

\author{
Antonio Carlos Homem Junior ${ }^{\mathrm{I}}$ Jane Maria Bertocco Ezequiel ${ }^{\mathrm{II}}$ \\ Daniela Junqueira Rodrigues" Rafael Silvio Bonilha PinheiroIII
}

\section{RESUMO}

Foram avaliados os efeitos da inclusão de grãos de girassol ou gordura protegida na dieta e da restrição e realimentação sobre a área de olho de lombo, espessura de gordura subcutânea, a composição centesimal, o teor de colesterol e a composição em ácidos graxos da gordura intramuscular do Longissimus lumborum de cordeiros, distribuidos em delineamento inteiramente casualizado, em esquema fatorial (3 dietas $x 2$ manejos de alimentação). O colesterol da gordura intramuscular de cordeiros alimentados com a dieta contendo gordura protegida $\left(28,5 \mathrm{mg} 100 \mathrm{~g}^{-1}\right)$ foi menor $(P<0,05)$ que o do controle $(36,8 \mathrm{mg}$

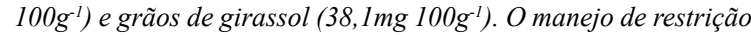
alimentar e realimentação não modificaram $(P>0,05)$ o perfil dos ácidos graxos, porém foi detectado que a dieta contendo grãos de girassol elevou $(P<0,05)$ a razão polinsaturado/ saturado, provavelmente pela superioridade $(P<0,05)$ de $20 \%$ na proporção de polinsaturados, reflexo direto do aumento na concentração do ácido linoleico. A inclusão de fontes lipídicas na dieta de ovinos é ferramenta que contribui para melhorar a qualidade da gordura intramuscular de cordeiros confinados, considerando que a gordura protegida reduz o teor de colesterol e que os grãos de girassol aumentam a concentração de ácidos graxos polinsaturados. $O$ manejo de alimentação com período de restrição e realimentação não altera a composição centesimal e a qualidade da gordura intramuscular.

Palavras-chave: ácido linoleico conjugado, composição centesimal, espessura de gordura subcutânea, gordura protegida, grãos de girassol.

\section{ABSTRACT}

It was evaluated the effects of sunflower grains inclusion or protected fat in the diet and compensatory growth on the loin eye area, subcutaneous fat thickness, chemical composition, cholesterol concentration and fatty acid composition of intramuscular fat of Longissimus lumborum of lambs distributed in a completely randomized design in factorial scheme (3 diets $x$ 2 feeding management). Intramuscular cholesterol from lambs fed with diet containing protected fat (28.5mg $\left.100 \mathrm{~g}^{-1}\right)$ was lower $(P<0.05)$ than that of the control $\left(36.8 \mathrm{mg} 100 \mathrm{~g}^{-1}\right)$ and

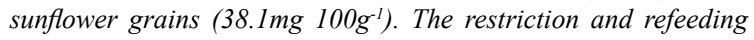
didn't cause change $(P>0.05)$ in the fatty acids profile, but diet containing sunflower grains increased polyunsaturated/saturated ratio due to $(P<0.05)$ the superiority of $20 \%$ in the proportion of polyunsaturated, reflecting directly the increase in linoleic acid. Inclusion of lipid sources in the diet of feedlot sheep is a tool that helps to improve the quality of intramuscular fat of lambs, whereas the protected fat reduces cholesterol and sunflower grains elevates the concentration of polyunsaturated fatty acids. Feeding restriction and refeeding period does not alter the chemical composition and quality of intramuscular fat.

Key words: chemical composition, conjugated linoleic acid, protected fat, fat thickness, sunflower grains.

\section{INTRODUÇ̃̃̃O}

$\mathrm{O}$ interesse em modificar a qualidade das carnes tem crescido nos últimos anos, com relação à composição química da carne, principalmente o teor de gordura, proteína e colesterol, além dos ácidos graxos da gordura intramuscular (WOOD et al., 2004). Nesse sentido, a inclusão de ingredientes fontes de lipídios, como os grãos de girassol e a gordura protegida, vêm sendo estudados (ARANA et al., 2006; MAPIYE et al., 2013) e, além da manipulação da formulação de dietas, o manejo de restrição e realimentação também pode corroborar as modificações da qualidade da carne.

'Centro Paula Souza, Faculdade de Tecnologia (Fatec), 15385-000, Taquaritinga, SP, Brasil. E-mail: achomemj@hotmail.com. Autor para correspondência.

"IFaculdade de Ciências Agrárias e Veterinárias (FCAV), Universidade Estadual Paulista (UNESP), Jaboticabal, SP, Brasil.

IIIFaculdade de Engenharia de Ilha Solteira (FEIS), UNESP, Ilha Solteira, SP, Brasil. 
A redução na ingestão de lipídios ricos em colesterol e ácidos graxos saturados e aumento no consumo de ácidos graxos mono e polinsaturados, atualmente é indicado na nutrição humana, a fim de reduzir os riscos de obesidade, câncer e doenças cardiovasculares (BESSA et al., 2000). Pela manipulação das formulações das rações, é possível aumentar os ácidos graxos polinsaturados na dieta, refletindo em aumento na proporção dos ácidos graxos polinsaturados na carne e no leite de animais ruminantes (JAKOBSEN, 1999; FERNANDES et al., 2008). Geralmente, incluir lipídios polinsaturados é mais eficaz em promover aumento nos ácidos graxos polinsaturados da carne que a inclusão de lipídios saturados (BOLTE et al., 2002; CASTRO et al., 2005; BAS et al., 2007), assim atendendo ao interesse do consumidor.

Neste trabalho, foram avaliados os efeitos do manejo de alimentação (não submetidos ao período de restrição alimentar ou com período de restrição e realimentação) e de dietas contendo grãos de girassol ou gordura protegida sobre a espessura de gordura subcutânea, área de olho de lombo, composição centesimal e teor de colesterol na carne, além dos ácidos graxos da gordura intramuscular do Longissimus lumborum de cordeiros confinados.

\section{MATERIAL E MÉTODOS}

O experimento foi realizado na Unidade Animal de Estudos Digestivos e Metabólicos do Departamento de Zootecnia da Faculdade de Ciências Agrárias e Veterinárias/UNESP, Campus de Jaboticabal, SP, Brasil.

Foram utilizados 36 ovinos machos não castrados da raça Santa Inês, com idade média de $108 \pm 6,1$ dias e peso médio de $18,7 \pm 2,5 \mathrm{~kg}$, alojados num galpão coberto, em baias individuais, providas por comedouros individuais e bebedouro para cada dois animais, com cama de bagaço de cana, que foi trocada semanalmente. Fez-se uma aplicação antihelmíntica e outra de vitamina ADE em todos os animais no início do experimento.

Três dietas foram avaliadas, a controle sem inclusão de fonte lipídica (DC), a com inclusão de grãos de girassol (DGG) e a com inclusão de gordura protegida (DGP). O volumoso (feno de Tifton-85) foi triturado em partículas de aproximadamente $5 \mathrm{~cm}$ e fornecido na relação volumoso:concentrado de 18:82 (Tabela 1). O volumoso e o concentrado foram misturados diariamente pela manhã, parcelados em duas refeições diárias (8 e 16 horas).

$\mathrm{O}$ período experimental foi de aproximadamente 84 dias, sendo 21 dias de adaptação às dietas e instalações. Após a adaptação, durante 21 dias, todos os 36 cordeiros (12 animais para cada dieta) receberam alimento à vontade. $\mathrm{O}$ período de restrição alimentar foi de 21 dias, em que 6 cordeiros de cada dieta passaram a receber $30 \%$ menos alimento em relação ao consumo apresentado no período sem restrição. Após o período de restrição alimentar, todos os cordeiros receberam, por 21 dias, alimento à vontade (realimentação). O manejo de alimentação à vontade para os cordeiros teve duração de 63 dias (MA) e de 42 dias para os que passaram por manejo de restrição alimentar (MR).

Os cordeiros foram abatidos ao final do período de realimentação, quando apresentavam $185 \pm 4,5$ dias de idade, peso corporal médio de $32,5 \pm 2,4 \mathrm{~kg}$ e condição corporal de 2,5 , numa escala de 1 a 5 (Russel et al., 1969). Após jejum de 16 horas de dieta sólida, os animais foram insensibilizados por eletro-narcose, pendurados de cabeça para baixo e cortadas as veias jugulares e artérias carótidas, objetivando a sangria. Após resfriamento da carcaça por 24 horas, foram efetuadas mensurações para cálculo da área de olho de lombo entre a $13^{\mathrm{a}}$ costela $\mathrm{e}$ $1^{\mathrm{a}}$ vértebra lombar (PINHEIRO et al., 2010). Coletouse uma amostra do músculo Longissimus lumborum, na qual se retirou toda gordura subcutânea, e foram analisados os teores de extrato etéreo, colesterol e ácidos graxos intramusculares. As amostras foram liofilizadas durante 72 horas e, após, determinouse a quantidade de água $\left(105^{\circ} \mathrm{C}\right)$, a proteína bruta, o extrato etéreo e a matéria mineral (SILVA \& QUEIROZ, 2002).

A quantidade de colesterol da carne foi determinada segundo BRAGAGNOLO \& RODRIGUEZ-AMAYA (1992). A extração de lipídios totais para determinação dos ácidos graxos foi realizada utilizando-se a técnica a frio, descrita por FOLCH et al. (1957). Para a transesterificação dos triacilgliceróis, foi utilizado o método 5509 da ISO (1978), em solução de n-heptano e KOH/ metanol. Os ésteres de ácidos graxos foram isolados e analisados através do cromatógrafo gasoso Shimadzu 14A, equipado com detector de ionização de chama e coluna capilar de sílica fundida $(50 \mathrm{~m}$ de comprimento, $0,25 \mathrm{~mm}$ de diâmetro interno e $0,20 \mathrm{~m}$ de Carbowax 20M). Os fluxos dos gases foram de $1,2 \mathrm{~mL}$ $\min ^{-1}$ para o gás de arraste $\left(\mathrm{H}_{2}\right) ; 30 \mathrm{~mL} \mathrm{~min}^{-1}$ para o gás auxiliar $\left(\mathrm{N}_{2}\right)$; e 30 e $300 \mathrm{~mL} \mathrm{~min}^{-1} \mathrm{de}_{2}$ e ar sintético, respectivamente. A temperatura inicial da coluna foi estabelecida em $150^{\circ} \mathrm{C}$, mantida por 3 minutos, sendo então elevada para $240^{\circ} \mathrm{C}$ a uma taxa de $10^{\circ} \mathrm{C} / \mathrm{min}$. Foi feita comparação com padrões de ésteres metílicos de ácidos graxos da Sigma. 
Tabela 1 - Composições em ingrediente e nutricional das dietas (\% MS).

\begin{tabular}{|c|c|c|c|}
\hline \multirow{2}{*}{ Ingrediente } & \multirow[b]{2}{*}{ DC } & \multirow[b]{2}{*}{ DGG } & \multirow[b]{2}{*}{ DGP } \\
\hline & & & \\
\hline Feno Tifton-85 & 18,0 & 18,0 & 18,0 \\
\hline Polpa cítrica & 35,5 & 29,5 & 28,5 \\
\hline Levedura de cana & 14,0 & 14,0 & 14,0 \\
\hline Casca de soja & 8,0 & 8,0 & 8,0 \\
\hline Farelo de girassol & 24,0 & 15,0 & 24,0 \\
\hline Grãos de girassol & - & 15,0 & - \\
\hline Gordura protegida $^{\circledR}$ & - & - & 7,0 \\
\hline Mistura mineral $^{1}$ & 0,5 & 0,5 & 0,5 \\
\hline \multicolumn{4}{|l|}{ Nutricional } \\
\hline Matéria seca (\%) & 90,1 & 90,2 & 90,3 \\
\hline Proteína bruta & 19,4 & 18,1 & 18,7 \\
\hline Extrato etéreo & 2,6 & 6,4 & 7,1 \\
\hline Fibra em detergente neutro & 49,3 & 51,4 & 51,2 \\
\hline Matéria mineral & 5,5 & 5,2 & 7,2 \\
\hline
\end{tabular}

${ }^{\circledR}$ Lacto-Plus; ${ }^{1}$ Níveis de garantia por kg: $50 \mathrm{~g}$ de P; $150 \mathrm{~g}$ de Ca; $195 \mathrm{~g}$ de Na; 20mg de Co; $190 \mathrm{mg}$ de Cu; 40mg de Iodo; $14500 \mathrm{mg}$ de Mn; $7 \mathrm{mg}$ de Se; 2000mg de Zn e 500mg de F; DC, dieta controle; DGG, dieta com grãos de girassol; DGP, dieta com gordura protegida.

Utilizou-se o delineamento inteiramente casualizado com seis tratamentos e seis repetições (cada animal uma unidade experimental) em esquema fatorial (3 dietas x 2 manejos de alimentação). Os dados foram submetidos ao teste $\mathrm{F}$ de análises de variância e, quando significativo em nível de 5\%, as médias foram comparadas pelo teste Tukey $(\mathrm{P}<0,05)$. As análises estatísticas foram realizadas pelo procedimento GLM (SAS, 2002) e, no modelo, incluía os efeitos da dieta, do manejo e suas interações.

\section{RESULTADOS E DISCUSSÃO}

Não houve interação manejo de alimentação e dieta $(\mathrm{P}>0,05)$, portanto são apresentados somente os efeitos principais. $\mathrm{O}$ manejo de alimentação ou a dieta não alteraram $(\mathrm{P}>0,05)$ as medidas realizadas no corte transversal do músculo Longissimus lumborum, apresentando valores médios para comprimento máximo de $5,7 \mathrm{~cm}$, largura máxima de $2,6 \mathrm{~cm}$, espessura de gordura subcutânea de $1,24 \mathrm{~mm}$ e área de olho de lombo de $11,7 \mathrm{~cm}^{2}$ (Tabela 2).

O manejo de alimentação ou a dieta não modificaram $(\mathrm{P}>0,05)$ a composição centesimal (g $100 \mathrm{~g}^{-1}$ de músculo) em água $(76,9)$, proteína bruta $(21,2)$, extrato etéreo $(1,9)$ e matéria mineral $(1,4)$. A restrição e realimentação não modificaram o perfil de ácidos graxos do músculo dos cordeiros $(\mathrm{P}>0,05)$, contrariando relatos de que o manejo de alimentação possa ser uma estratégia para controlar a composição dos ácidos graxos da carne (RAES et al., 2004).

Neste trabalho (Tabela 2), a composição centesimal da carne foi semelhante à obtida por outros autores, os quais mostram que a inclusão de fontes lipídicas na dieta não modificou a composição centesimal do músculo (MADRUGA et al., 2006; ARANA et al., 2006; MADRUGA et al., 2008; MACEDO et al., 2008; MANSO et al., 2009), provavelmente, devido ao peso de abate igual entre os animais. Valores de 0,95 a 3,78\% na concentração de gordura intramuscular do músculo Biceps femoris podem ocorrer entre os pesos de abate de 15 a $45 \mathrm{~kg}$ (BONAGURIO et al., 2004). Por outro lado, a quantidade de água no músculo pode diminuir e, a de extrato etéreo aumentar, pela inclusão de óleo de milho na dieta de cordeiros (RUSSO et al., 1999).

A dieta com gordura protegida reduziu $(\mathrm{P}<0,05)$ o colesterol na gordura intramuscular em relação às dietas controle e grãos de girassol, estas últimas não diferiram $(\mathrm{P}>0,05)$ entre si (Tabela 2). Os grãos de girassol são fontes lipídicas não protegidas e, no rúmen, os ácidos graxos são saturados pelo processo de biohidrogenação, o que reduz a disponibilidade para absorção intestinal de polinsaturados, os quais apresentam caráter hipocolesterêmico, que pode ser responsável pela redução do colesterol. A substituição do farelo de soja pela semente de uva reduziu o colesterol de 
Tabela 2 - Medidas objetivas e composição centesimal do músculo Longissimus lumborum de cordeiros confinados.

\begin{tabular}{|c|c|c|c|c|c|c|c|c|}
\hline \multirow{2}{*}{ Medida } & \multicolumn{2}{|c|}{--------Manejo-------- } & \multirow{2}{*}{$\mathrm{P}$} & \multicolumn{3}{|c|}{----------------------Dieta---------------------- } & \multirow{2}{*}{$\mathrm{P}$} & \multirow{2}{*}{ EQM } \\
\hline & MA & MR & & $\mathrm{DC}$ & DGG & DGP & & \\
\hline $\mathrm{N}$ & 18 & 18 & - & 12 & 12 & 12 & - & - \\
\hline $\mathrm{A}(\mathrm{cm})$ & 5,6 & 5,7 & 0,188 & 5,8 & 5,6 & 5,7 & 0,335 & 3,6 \\
\hline $\mathrm{B}(\mathrm{cm})$ & 2,5 & 2,7 & 0,155 & 2,5 & 2,7 & 2,6 & 0,171 & 2,2 \\
\hline EGS (cm) & 0,14 & 0,11 & 0,123 & 0,11 & 0,12 & 0,15 & 0,081 & 0,4 \\
\hline $\mathrm{AOL}\left(\mathrm{cm}^{2}\right)$ & 11,3 & 12,1 & 0,053 & 11,5 & 11,7 & 11,8 & 0,758 & 1,2 \\
\hline Água & 77,0 & 76,7 & 0,248 & 77,1 & 76,8 & 76,8 & 0,670 & 0,8 \\
\hline Proteína bruta & 21,1 & 21,3 & 0,618 & 21,1 & 21,2 & 21,3 & 0,944 & 0,9 \\
\hline Extrato etéreo & 1,9 & 1,8 & 0,763 & 1,8 & 1,9 & 1,9 & 0,647 & 0,5 \\
\hline Matéria mineral & 1,3 & 1,4 & 0,574 & 1,3 & 1,3 & 1,6 & 0,154 & 0,5 \\
\hline Colesterol (mg 100g $\left.{ }^{-1}\right)$ & 34,2 & 34,7 & 0,860 & $36,8 \mathrm{a}$ & $38,0 \mathrm{a}$ & $28,5 \mathrm{~b}$ & 0,006 & 0,07 \\
\hline
\end{tabular}

a, bMédias seguidas por letras iguais não diferem pelo teste Tukey (P>0,05); N, número de repetições; $\mathrm{P}$, valor da probabilidade; EQM, erro quadrado da média; A, comprimento máximo obtido no corte transversal do lombo; B, largura máxima obtida no corte transversal do lombo; EGS, espessura de gordura subcutânea; AOL, área de olho de lombo. MA, manejo de alimentação à vontade; MR, manejo de restrição alimentar e realimentação. DC, dieta controle; DGG, dieta com grãos de girassol; DGP, dieta com gordura protegida.

77,2 para $70,4 \mathrm{mg}^{100 \mathrm{~g}^{-1}}$ sem alterar o teor de lipídio do lombo de ovinos (SOLOMON et al., 1991), mas, ao incluir óleo de milho ou caroço de algodão, não houve relatos de alteração na concentração do colesterol da gordura intramuscular de cordeiros (RUSSO et al., 1999; MADRUGA et al., 2008).

A adição de 6,$6 ; 13,2$; e $19,8 \%$ de grãos de girassol ou a inclusão de $4 \%$ de óleo de girassol na dieta de cordeiros reduziu a concentração do ácido palmítico e elevou a de vacênico (precursor do ácido linoleico conjugado) na gordura intramuscular, sem alteração na composição centesimal do músculo (MACEDO et al., 2008; MANSO et al., 2009). Porém, nenhum efeito ocorreu ao utilizar $4 \%$ de óleo vegetal hidrogenado (MANSO et al., 2009).

As proporções dos ácidos graxos saturados e monoinsaturados não foram influenciadas $(\mathrm{P}>0,05)$ pelas dietas, porém a concentração dos polinsaturados foi superior $(\mathrm{P}<0,05)$ naqueles animais alimentados com dieta contendo grãos de girassol. Os ácidos graxos presentes em maiores proporções na gordura intramuscular do lombo de cordeiros confinados foram, em ordem decrescente (Tabela 3), o monoinsaturado 18:1C9 (Oléico), seguido pelos saturados 16:0 (Palmítico) e 18:0 (Esteárico). Pela inclusão de fontes lipídicas, busca-se melhorar a qualidade da gordura com o aumento na concentração de ácidos graxos insaturados e diminuição dos saturados na carne de animais ruminantes, mas nem sempre se obtém melhorias no perfil de ácidos graxos, pois existem inúmeros fatores influentes como o tipo e a concentração de lipídio e a proporção de concentrado das dietas. Numa dieta composta por concentrado e feno de cevada, oferecida à vontade, contendo $5 \%$ de ácido oléico protegido, ou numa dieta com $30 \%$ de feno de Tifton e adição de 20,30 ou $40 \%$ de caroço de algodão, não houve modificações nas proporções de ácidos graxos saturados e insaturados (ARANA et al., 2006; MADRUGA et al., 2008). No entanto, a inclusão de grãos de girassol melhorou o perfil dos ácidos graxos da gordura intramuscular de cordeiros (MACEDO et al., 2008).

As proporções dos ácidos graxos obtidas (Tabela 3) estão de acordo com a literatura (MADRUGA et al., 2006; MAPIYE et al., 2013) e demonstram a necessidade de reduzir o teor dos saturados, que é muito elevado na gordura intramuscular de ruminantes, e de aumentar o teor dos polinsaturados, principalmente o ácido linoleico conjugado (ALC), na tentativa de melhorar a aceitação da carne pelos consumidores preocupados em consumir alimentos mais saudáveis.

A inclusão de grãos de girassol aumentou $(\mathrm{P}<0,05)$ a concentração do 18:2 (Linoleico) no músculo dos cordeiros, porém nenhum efeito $(\mathrm{P}>0,05)$ foi detectado nos demais ácidos graxos (Tabela 3). A biohidrogenação ruminal dos ácidos graxos polinsaturados poder ser reduzida em $\mathrm{pH}$ ruminal mais ácido, assim diminuindo a formação de ALC e do seu precursor 18:1 T11 (Vacênico). 
Tabela 3 - Alguns ácidos graxos da gordura intramuscular do Longissimus lumborum de cordeiros confinados ( $\mathrm{mg} \mathrm{g}^{-1}$ de ácido graxo).

\begin{tabular}{|c|c|c|c|c|c|c|c|c|}
\hline \multirow{2}{*}{ Ácido graxo } & \multicolumn{2}{|c|}{---------Manejo----------- } & \multirow{2}{*}{$\mathrm{P}$} & \multicolumn{3}{|c|}{---Dieta----------------------- } & \multirow{2}{*}{$\mathrm{P}$} & \multirow{2}{*}{ EQM } \\
\hline & MA & MR & & $\mathrm{DC}$ & DGG & DGP & & \\
\hline $\mathrm{N}$ & 18 & 18 & - & 12 & 12 & 12 & - & - \\
\hline 14:0 (Mirístico) & 18,1 & 18,4 & 0,723 & 18,2 & 18,3 & 18,2 & 0,987 & 24,3 \\
\hline 16:0 (Palmítico) & 239,3 & 245,6 & 0,459 & 249,3 & 240,1 & 238,0 & 0,515 & 25,4 \\
\hline 17:0 (Heptadecanóico) & 14,0 & 12,6 & 0,071 & 13,0 & 13,2 & 13,8 & 0,637 & 2,30 \\
\hline 18:0 (Esteárico) & 148,9 & 144,2 & 0,441 & 145,1 & 142,8 & 151,8 & 0,452 & 17,9 \\
\hline 16:1 (Palmitolêico) & 19,1 & 18,1 & 0,334 & 19,5 & 18,3 & 18,0 & 0,416 & 29,2 \\
\hline 18:1 cis (Oléico) & 391,4 & 366,6 & 0,064 & 395,0 & 370,6 & 371,5 & 0,232 & 38,8 \\
\hline 18:1trans (Vacênico) & 29,6 & 42,3 & 0,182 & 28,3 & 35,1 & 44,3 & 0,380 & 27,9 \\
\hline 18:2c9c12 (Linoléico) & 79,7 & 91,2 & 0,071 & $76,1 \mathrm{~b}$ & $95,8 \mathrm{a}$ & $84,5 \mathrm{ab}$ & 0,045 & 18,5 \\
\hline 18:2c9t11 (ALC) & 11,5 & 12,6 & 0,586 & 10,4 & 13,3 & 12,5 & 0,514 & 6,20 \\
\hline 22:1 (Erúcico) & 27,6 & 28,12 & 0,780 & $24,6 b$ & $32,1 \mathrm{a}$ & $27,1 \mathrm{ab}$ & 0,027 & 6,50 \\
\hline Saturado & 428,5 & 428,7 & 0,966 & 433,2 & 422,8 & 429,8 & 0,315 & 16,8 \\
\hline Monoinsaturado & 474,8 & 460,6 & 0,076 & 473,9 & 462,1 & 467,1 & 0,469 & 23,1 \\
\hline Polinsaturado & 96,0 & 108,7 & 0,095 & $91,1 \mathrm{~b}$ & $114,6 \mathrm{a}$ & $101,3 \mathrm{ab}$ & 0,047 & 22,3 \\
\hline $\mathrm{P} / \mathrm{S}$ & 2,2 & 2,5 & 0,121 & $2,1 \mathrm{~b}$ & $2,7 \mathrm{a}$ & $2,4 \mathrm{ab}$ & 0,035 & 0,56 \\
\hline
\end{tabular}

${ }^{a}$, ${ }^{b}$ édias seguidas por letras iguais não diferem pelo teste Tukey $(\mathrm{P}>0,05)$; N, número de repetições; $\mathrm{P}$, valor da probabilidade; EQM, erro quadrado da média; ALC, ácido linoléico conjugado; Saturados $(10: 0+12: 0+14: 0+15: 0+16: 0+17: 0+18: 0+22: 0+24: 0)$; Monoinsaturados $(12: 1+14: 1+16: 1+17: 1+18: 1+22: 1)$; Polinsaturados $(18: 2+18: 3+22: 2+20: 5)$; MA, manejo de alimentação à vontade; MR, manejo de restrição alimentar e realimentação; DC, dieta controle; DGG, dieta com grãos de girassol; DGP, dieta com gordura protegida; P/S, razão Polinsaturados/Saturados.

BESSA et al. (2005) verificaram redução dos ácidos graxos saturados 16:0 e 17:0, devido à inclusão do óleo de soja nas dietas, ainda relatou aumento no teor de ALC pela inclusão de óleo somente nas dietas com elevada proporção de volumoso e não nas dietas com elevado teor de concentrado. No entanto, a inclusão de grãos de girassol na dieta dos animais pode trazer benefícios para a saúde do consumidor. KHANAL \& OLSON (2004) relataram que o teor de ALC pode variar de 0,6 a $15 \mathrm{mg}$ de $\mathrm{ALC} \mathrm{g}^{-1}$ de ácido graxo e que, dentre os fatores que modificam essa concentração, a dieta é o principal fator que precisa ser elucidado, a fim de enriquecer os produtos de ruminantes (leite e carne). Neste estudo, foram obtidos valores de concentração do ALC (Tabela 3) próximos ao limite superior indicado pelos autores supracitados.

A razão polinsaturado/saturado se elevou devido à inclusão do grão do girassol à dieta $(\mathrm{P}<0,05)$ em relação ao controle, mas sem diferir da dieta com gordura protegida (Tabela 3 ), fato este que pode ser atribuído ao aumento de $20 \%(\mathrm{P}<0,05)$ no teor de ácidos graxos polinsaturados na gordura. ARANA et al. (2006), testando a inclusão do óleo de oliva na dieta de ovinos, relataram ausência de efeito sobre a razão $\mathrm{P} / \mathrm{S}$, que variou de 0,43 a 0,47 .

\section{CONCLUSÃO}

A inclusão de fontes lipídicas na dieta de ovinos é ferramenta que contribui para melhorar a qualidade da gordura intramuscular de cordeiros confinados, considerando que a gordura protegida reduz o teor de colesterol, os grãos de girassol aumentam a concentração de ácidos graxos polinsaturados em relação à dieta sem inclusão de fonte de lipídios.

Não há alteração na espessura de gordura subcutânea pela inclusão de lipídios protegidos ou não à dieta, quando os animais são abatidos com peso corporal semelhante. O manejo de alimentação com período de restrição e realimentação não altera a composição centesimal e a qualidade da gordura intramuscular.

\section{AGRADECIMENTOS}

À Fundação de Amparo à Pesquisa do Estado de São Paulo (FAPESP), pelo financiamento desta pesquisa. À Caramuru Alimentos S/A, pelos ingredientes fornecidos (casca de soja, 
farelo de girassol e grãos de girassol). Ao Grupo Dalquim, pela gordura protegida.

\section{REFERÊNCIAS}

ARANA, A. et al. Effect of feeding lambs oleic acid calcium soaps on growth, adipose tissue development and composition. Small Ruminant Research, v.63, n.1-2, p.75-83, 2006. Disponìvel em: <http://www.journals.elsevierhealth.com/periodicals/rumin/ article/S0921-4488(05)00055-6/abstract. $>$. Acesso em: 15 set. 2013. doi: $10.1016 /$ j.smallrumres.2005.02.006.

BAS, P. et al. Effect of level of linseed of fatty acid composition of muscles and adipose tissues of lambs with emphasis on trans fatty acids. Meat Science, v.77, n.4, p 678-688, 2007. Disponível em: $<\mathrm{http}: / / \mathrm{www} . s c i e n c e d i r e c t . c o m / s c i e n c e / a r t i c l e / p i i /$ S0309174007001805.>. Acesso em: 15 set. 2013. doi:10.1016/j. meatsci.2007.05.022.

BESSA, R.J.B. et al. Effect of lipid supplementation on growth performance, carcass and meat quality and fatty acid composition of intramuscular lipids of lambs fed dehydrated lucerne or concentrate. Livestock Production Science, v.96, n.2-3, p.185194, 2005. Disponível em: <http://www.sciencedirect.com/ science/article/pii/S0301622605000576.>. Acesso em: 15 set. 2013. doi:10.1016/j.livprodsci.2005.01.017.

BESSA, R.J.B. et al. Reticulo-rumen biohydrogenation and the enrichment of ruminant edible products with linoleic acid conjugated isomers. Livestock Production Science, v.63, n.3, p.201-211, 2000. Disponível em: $<$ http://www.sciencedirect.com/ science/article/pii/S0301622699001177.>. Acesso em: 15 set. 2013. PII: S0301-6226(99)00117-7.

BOLTE, M.R. et al. Feeding lambs high-oleate or high-linoleate safflower seeds differentially influences carcass fatty acid composition. Journal of Animal Science, v.80, n.3, p.609-616, 2002. Disponível em: $<\mathrm{http} / / / \mathrm{www}$.journalofanimalscience.org/ content/80/3/609.long.>. Acesso em: 26 out. 2013.

BONAGURIO, S. et al. Composição centesimal da carne de cordeiros Santa Inês puros e mestiços com Texel abatidos com diferentes pesos. Revista Brasileira de Zootecnia, v.33, n.6, p.2387-2393, 2004. Disponível em: <http://www.scielo.br/pdf/ rbz/v33n6s3/23443.pdf.>. Acesso em: 16 nov. 2012. doi: 10.1590/ S1516-35982004000900027.

BRAGAGNOLO, N.; RODRIGUES-AMAYA, D.B. Teores de colesterol em carne de frango. Revista de Farmácia e Bioquímica da Universidade de São Paulo, v.28, n.2, p.122-131, 1992.

CASTRO, T. et al. Fatty acid composition and carcass characteristics of growing lambs fed diets containing palm oil supplements. Meat Science, v.69, n.4, p.757-764, 2005. Disponível em: $<$ http://www.sciencedirect.com/science/article/pii/ S0309174004002906. >. Acesso em: 16 nov. 2012. doi:10.1016/j. meatsci.2004.11.008.

FERNANDES, M.F. et al. Características físico-químicas e perfil lipídico do leite de cabras mestiças Moxotó alimentadas com dietas suplementadas com óleo de semente de algodão ou girassol. Revista Brasileira de Zootecnia, v.37, n.4, p.703710, 2008. Disponível em: <http://www.scielo.br/pdf/rbz/ v37n4/17.pdf. $>$. Acesso em: 26 set. 2013. doi: 10.1590/S151635982008000400017.
FOLCH, J. et al. A simple method for the isolation and purification of total lipids from animal tissues. Journal of Biological Chemistry, v.226, p.497-509, 1957.

INTERNATIONAL ORGANIZATION FOR STANDARDIZATION. EN ISO 5509: animal and vegetable fats and oils: preparation of methyl esters of fatty acids. London 1978. Disponível em: <http:// www.iso.org/iso/iso_catalogue/catalogue_ics/catalogue_detail_ics. htm?csnumber=11560.>. Acesso em: 10 maio 2014.

JAKOBSEN, K. Dietary modifications of animal fats: status and future perspectives. Fett-Lipid, v.101, n.12, p.475483, 1999. Disponível em: <http://onlinelibrary.wiley. comn.>. Acesso em: 10 maio 2014. doi: 10.1002/(SICI)15214133(199912)101:12<475::AID-LIPI475>3.0.CO;2-H.

KHANAL, R.C.; OLSON, K.C. Factors affecting conjugated linoleic acid (CLA) content in milk, meat, and egg: a review. Pakistan Journal of Nutrition, v.3, n.2, p.82-98, 2004. Disponível em: $<$ http://scialert.net/qredirect.php?doi=pjn.2004 $.82 .98 \&$ linkid=pdf. $>$. Acesso em: 26 set. 2013. doi:10.3923/ pjn.2004.82.98.

MACEDO, V.P. et al. Composições tecidual e química do lombo de cordeiros alimentados com rações contendo semente de girassol em comedouros privativos. Revista Brasileira de Zootecnia, v.37, n.10, p.1860-1868, 2008. Disponível em: <http://www. revista.sbz.org.br/artigo/visualizar.php? artigo $=7227 .>$. Acesso em: 26 set. 2013. doi: 10.1590/S1516-35982008001000021.

MADRUGA, M.S. et al. Efeito de dietas com níveis crescentes de caroço de algodão integral sobre a composição química e o perfil de ácidos graxos da carne de cordeiros Santa Inês. Revista Brasileira de Zootecnia, v.37, n.8, p.1496-1502, 2008. Disponível em: <http://www.revista.sbz.org.br/artigo/visualizar. php?artigo $=7117$. $>$. Acesso em: 26 set. 2013. doi: 10.1590/ S1516-35982008000800023.

MADRUGA, M.S. et al. Efeito do genótipo e do sexo sobre a composição química e o perfil de ácidos graxos da carne de cordeiros. Revista Brasileira de Zootecnia, v.35, n.4, p.18381844, 2006. Disponível em: <http://www.scielo.br/pdf/rbz/ v35n4s0/a35v354s.pdf. $>$. Acesso em: 10 dez. 2012. doi: 10.1590/ S1516-35982006000600035.

MANSO, T. et al. Animal performance and fatty acid composition of lambs fed with different vegetable oils. Meat Science, v.83, n.3, p.511-516, 2009. Disponível em: <http://www.sciencedirect.com/ science/article/pii/S0309174009001934.>. Acesso em: 26 out. 2013. doi: 10.1016/j.meatsci.2009.06.035.

MAPIYE, C. et al. Effects of feeding flaxseed or sunflowerseed in high-forage diets on beef production, quality and fatty acid composition. Meat Science, v.95, n.1, p.98-109, 2013. Disponível em: <http://www.sciencedirect.com/science/article/ pii/S0309174013001113.>. Acesso 17 nov. 2013. doi: 10.1016/j. meatsci.2013.03.033.

PINHEIRO, R.S.B. et al. Correlações entre medidas determinadas in vivo por ultrassom e na carcaça de ovelhas de descarte. Revista Brasileira de Zootecnia, v.39, n.5, p.1161-1167, 2010. Disponível em: <http://www.scielo.br/scielo.php?pid=S1516$35982010000500030 \&$ script $=$ sci arttext. $>$. Acesso em: 26 set. 2013. doi: $10.1590 / \mathrm{S} 1516-35982010000500030$. 
RAES, K. et al. Effect of dietary fatty acids on incorporation of long chain polyunsaturated fatty acids and conjugated linoleic acid in lamb, beef and pork meat: a review. Animal Feed Science and Technology, v.113, n.1-4, p.199-221, 2004. Disponível em: <http:// www.sciencedirect.com/science/article/pii/S0377840103002530.>. Acesso em: 10 dez. 2012. doi:10.1016/j.anifeedsci.2003.09.001.

RUSSEL, A.J.F. et al. Subjective assessment of body fat in live sheep. Journal of Agricultural Science, v.72, n.3, p.451-454, 1969. Disponível em: <http://journals.cambridge.org/action/dis playAbstract fromPage $=$ online $\&$ aid $=4572240$. $>$. Acesso em: 10 ago. 2013. doi: 10.1017/S0021859600024874.

RUSSO, C. et al. Effect of diet energy source on the chemical physical characteristics of meat and depot fat of lambs carcasses. Small Ruminant Research, v.33, n.1, p.77-85, 1999. Disponível em: $<$ http:// www.sciencedirect.com/science/article/pii/S0921448898002004.>. Acesso em: 26 set. 2013. doi :10.1016/S0921-4488(98)00200-4.
SAS/STAT ${ }^{\circledR}$ Versão 9.0 do sistema SAS para Windows, copyright 2002. Cary, NC, 2002.

SILVA, D.J.; QUEIROZ, C. Análise de alimentos (métodos químicos e biológicos). Viçosa, MG: Universidade Federal de Viçosa, 2002. 235p.

SOLOMON, M.B. et al. Influence of rapeseed meal, whole rapeseed, and soybean meal on fatty acid composition and cholesterol content of muscle and adipose tissue from ram lambs. Journal of Animal Science, v.69, n.10, p.4055-4061, 1991. Disponível em: <http://www.journalofanimalscience.org/ content/69/10/4055.long. $>$. Acesso em: 12 ago. 2013.

WOOD, J.D. et al. Effects of fatty acids on meat quality: a review. Meat Science, v.66, n.1, p.21-32, 2004. Disponível em: <http://www. sciencedirect.com/science/article/pii/S0309174003000226\#.>. Acesso em: 26 out. 2013. doi:10.1016/S0309-1740(03)00022-6. 